\title{
ESPACO ABERTO
}

IDENTIDADES, DISCURSOS E FRONTEIRAS: (RE)PENSANDO ENVELHECIMENTO

\author{
João Paulo Ferreira da Silva ${ }^{1}$ \\ Keika Inouye ${ }^{2}$ \\ Fabiana de Souza Orlandi ${ }^{3}$ \\ Sofia Cristina lost Pavarini ${ }^{4}$
}

resumo

o processo de envelhecer tem feito emergir inúmeras questões sobre como manter-se ativo e saudável a certo preço. Seja pelo advento de novas técnicas cirúrgico-plásticas, seja através da mídia, seja por consequências culturais, sociais e históricas, o corpo jovem/belo/sarado tem ganhado cada vez mais espaço e relegado, inversamente, ao corpo velho, o estigma da degeneração física e social. Esse preço tem custado intensas adequa-

1 Graduando em Gerontologia. Universidade Federal de São Carlos (UFSCar), Departamento de Gerontologia. E-mail: joaopauloferreira@outlook.com

2 Farmacêutica-bioquímica e Doutora em Educação Especial. Professora Adjunta da Universidade Federal de São Carlos (UFSCar), vinculada ao Departamento de Gerontologia. E-mail: keikain@terra.com.br 3 Enfermeira e doutora em Ciências. Professora Adjunta da Universidade Federal de São Carlos (UFSCar), vinculada ao Departamento de Gerontologia. E-mail: forlandi@ufscar.br

4 Enfermeira, Doutora em Educação e Pós-Doutoranda em Gerontologia. Professora Associada da Universidade Federal de São Carlos (UFSCar), vinculada ao Departamento de Gerontologia. E-mail: sofia@ufscar.br 
ções sociais aos padrões hegemônicos de identidade, de corpo e de saúde tidos como normais, ressignificando fronteiras entre ser normal e ser patológico, ser jovem e ser velho e instituindo verdadeiros "marcadores coletivos" de controle e de disciplinamento/ normalização estético-social.

palavras - chave

Envelhecimento. Corpo. Gerontologia. Discursos. Normalização.

\begin{abstract}
Talvez queiram nos objetar que temos tendência para confundir a saúde com juventude. Não esquecemos, no entanto, de que a velhice é um estágio normal da vida. Mas, com idades iguais, será sadio um velho que manifestar uma capacidade de adaptação ou de reparação dos desgastes orgânicos que outro não manifeste; por exemplo: uma perfeita e sólida soldadura do colo do fêmur fraturado. Um velho saudável não é apenas uma ficção de poeta (CANGUILHEM, 1982, p. 163).
\end{abstract}

Contemporaneamente, vê-se que questões relacionadas ao envelhecimento/ velhice têm tomado cada vez mais espaço nos setores sociais, programas de saúde, nas políticas públicas, pesquisas demográficas e epidemiológicas e em debates mais acalorados envolvendo diferentes contextos socioculturais e idosos. Não tardou para que corolário a esse fenômeno de "envelhecimento sentido" surgisse outras variáveis de forma a reiterar tal processo, afirmando-o, (re)instituindo e (des)centralizando seu lócus a partir de novos saberes que o são, eles próprios, seus constituintes.

Nesse sentido, é visível que a maior parte das questões envolvendo envelhecimento constitui-se, quase que de forma ritualizada, a uma matriz biológica - "normatividade biológica" ${ }^{5 "}$-, cercada por instrumentos avaliativos que pouco ou quase nada têm a dizer sobre envelhecer de fato ou sobre investigações mais introspectivas, antes, por um mecanismo mais polido de normalização/enquadramento, adequação social, contabilização estatística e de controle dos dissidentes (CANGUILHEM, 1982).

Evocar questões sobre envelhecimento populacional em época de pós-transição demográfica e epidemiológica é, por vezes, colocar em xeque realidades heterogêneas diante de um regime mais hegemônico de (in)visibilidade. Esses valores/normas hegemônicos assumem diferentes formas e

5 Sobre o conceito de "normatividade biológica", ver Canguilhem, 1982, p. 97. 
nomenclaturas particulares, como, por exemplo, o conceito de qualidade de vida que, desde fins do século $X X$, tem tendenciado e gestado o cerne das questões sobre envelhecimento ativo e saudável, ora em regimes de visibilidade, ora de invisibilidade.

Os indivíduos que estão submetidos a um "campo de visibilidade" e possuem essa relação de consciência do estado de "ser visto/visível" assumem por conta própria as fronteiras do poder. Colocam-nas em ação de forma sutil e imperceptível - que tende ao incorpóreo - sobre si; inscrevem-se em economias de poderes as quais desempenham papel duplo; configuram-se como ponto de partida à própria sujeição. Aquilo que é construído, pensado e repetido por antecipação. E, por conseguinte, reproduzindo um ideário de juventude psíquico-estética, de corporalidade, "modernidade comportamental" e inserção social, fazendo, paradoxalmente, um contraste com a velhice e dicotomizando essas diferenças, onde, muito embora, ser velho/idoso chega a ser anacrônico e corporalmente/socialmente inadequado. Tendo-se, contudo, que:

Um corpo inadequado não apenas marca a maior parte da população como gorda, feia ou disforme, segundo os padrões modelares de uma elite, mas também gera subjetividades autodestrutivas em sua busca de adequação a qualquer custo (MISKOLCl, 2006, p. 685).

Não é mero acaso que se tenha assistido, já no século XVIII, o surgimento de sistemas hierárquicos de vigilância, enquadramento e outras técnicas disciplinares que mantém, até hoje, uma economia política sobre os corpos e um adestramento/correção dessas diferenças. Entende-se por "correção" uma forma sistemática e nada centralizada de utilizar essa(s) mesma(s) diferença(s) como marcadores sociais de uma norma que é, ela própria, reguladora e mantenedora de todos esses processos subjacentes.

Outras "inovações" desse projeto econômico-político foram as criações de processos que permitiam - e ainda permitem - avaliar o indivíduo e retroalimentar as relações entre saberes e poderes existentes, "à organização de campos comparativos que permitam classificar, formar categorias, estabelecer médias, fixar normas" (FOUCAULT, 1997, p. 182).

E pensar que esse escrutínio era até a segunda metade do século XVIII sinônimo de privilégio social, uma vez que, observar e descrever fazia parte dos chamados "rituais de poderio" - dirigido, sobretudo, às elites da época. Uma espécie de crônica de uma vida a ser copiada, lembrada e repetida. Agora, no entanto, como método de dominação e controle, mas também passível de repetições e polarizações. 
É como se assumíssemos uma posição de nivelamento social, onde as diferenças do processo de envelhecimento pudessem seguir uma "bula" prescritiva e normativa instrumentalizada, na medida em que fossem replicados certos comportamentos tidos como "saudáveis" e distribuídos modelos de enfrentamento às vicissitudes que não estivessem condizentes com o modelo hegemônico de idoso, pois,

[...] o homem só se sente em boa saúde, quando se sente mais do que o normal, isto é, não apenas adaptado ao meio e às suas exigências, mas, também, normativo, capaz de seguir novas normas de vida (CANGUILHEM, 1982, p.161).

A não normalidade/desvio passaria, portanto, da subjetividade para negligência, onde esses mesmos indivíduos deveriam, obrigatoriamente, assujeitarem-se aos bens e serviços capazes de oferecer apoio/suporte e cura/tratamento para o que não fosse considerado normal - patológico - ou enfrentar o estigma da degeneração fisiológica e social (DEBERT, 1999).

É assustador perceber como a velhice tem sido compreendida e, porque não, propagandeada/vendida a partir de termos tão contraditórios e alicerçados como a própria construção de ser velho, relegando, muito frequentemente, a padrões normativos de corpo, de classe, de sexualidade e de identidade.

Essas diferenças que envolvem classe, raça/etnia, gênero, sexualidade e geração, construídas historicamente, passam muitas vezes percebidas como parte corpórea natural do indivíduo, o que, por isso mesmo, podem ser alteradas por técnicas de adequação corporal - social (MISKOLCI, 2006).

A Gerontologia, no entanto, se constitui hoje como área do conhecimento que estuda o processo de envelhecimento humano em todas as suas peculiaridades, dimensões e contextos (NERI, 2007). Por ser um campo multidimensional e interdisciplinar, nota-se um despertar constante pelos setores da sociedade em relação ao envelhecimento humano (PRADO; SAYD, 2006). Aponta-se estatisticamente de acordo com a Organização Mundial da Saúde (OMS) que em 2020 o Brasil alcance a marca de 32 milhões de idosos, ficando no sexto lugar da lista de países com maior número de idosos - cerca de $15 \%$ da população total do país naquele ano.

É, portanto, dentro desse cenário ampliado de velhice que se insere inúmeros estudos em relação ao envelhecimento humano a outros tantos conceitos. Na tentativa de ampliar o debate e o reflexo dos estudos em Gerontologia, muitas questões voltam à tona - como, por exemplo, a fronteira entre juventude/velhice - e devem ser problematizadas constantemente em virtude 
de um processo de envelhecer pautado em relações mais "humanizadas" de cuidado, autoestima, autoconceito, senso de auto-eficácia, bem estar subjetivo, convivência, adoecimento e, por consequência, menos biomédicas (NERI, 2007). Coexistem, ainda, muitos outros entraves que fazem parte dos discursos sobre envelhecimento, como, por exemplo, o conceito de saúde.

A grande questão é, sobretudo, que não sejamos ascéticos para conceitos tão usuais e comuns, que, no fundo, não são nada mais do que caracterizações biológicas normativas que, em virtude de um discurso protecionista e essencialista, definem as fronteiras entre normalidade e anormalidade, onde a segunda não se limita a caracterizações, atributos e alterações físicas e fisiológicas, antes, num sentido mais amplo, influindo também nas relações sociais estabelecidas com o meio e a sua capacidade de criar novas normas a partir de determinados "desvios". Entende-se por norma, aquilo que:

Corresponde à aparição de um bio-poder, isto é, de um poder sobre a vida e das formas de governamentabilidade que a ela estão ligadas: o modelo jurídico da sociedade, elaborado entre os séculos XVII e XVIII, sucumbe a um modelo médico, em sentido amplo, e assiste-se ao nascimento de uma verdadeira "medicina social" que se ocupa de campos de intervenção que vão bem além do doente e da doença (REVEL, 2005, p. 65).

Ou seja, poder-se-ia perceber como as identidades se movimentam, se multiplicam e se constroem imbricadas em um esquadro marcado por relações normativas e de valores, já que "nossa imagem do mundo é sempre também um quadro de valores" (CANGUILHEM, 1982, p. 143). Em se tratando das questões modelares de imagem e de valores, vê-se, contudo, o papel da mídia, por exemplo, que enfatiza e reproduz diariamente a representação social do corpo, imagem, saúde, beleza, qualidade de vida e bem-estar perfeitos. Tais representações, em outras palavras, são:

[...] construções sociais simbólicas e culturais diárias, além de historicamente contingentes, com implicações (in)diretas nas microfísicas de poder - econômico e político - nas mais diversificadas esferas da vida (CARVALHO; ADELMAN; ROCHA, 2007, p. 126).

A velhice e a geração estão costumeiramente transcritas em um ritmo biológico da vida, onde analisar/ver a velhice e o processo de envelhecimento a partir de ritmos biológicos poderia se configurar em um erro, recaindo, portanto, em processos naturalizantes e normativos (MANNHEIM, 1982). Faz-se neces- 
sário, tanto para os estudos em gerontologia, quanto para as demais "ciências" do envelhecimento, ver como o processo de envelhecer é, antes de qualquer coisa, marcado por relações/práticas hierárquicas de exclusão e terminologias conservadoras que apregoam qualidade de vida, sendo subsidiadas por saberes médicos e técnicas terapêuticas ultramodernas.

Esses métodos que permitem o controle minucioso das operações do corpo, que realizam a sujeição constante de suas forças e lhes impõem uma relação de docilidade-utilidade, são os que podemos chamar de "disciplinas" (FOUCAULT, 1997, p. 133).

A saber, a própria regulamentação e interpelação do termo "ciência" a partir da modernidade já se tornava destinatário de uma prática criada para (re)afirmar saberes e fabricar sujeitos.

[...] a regulamentação é um dos grandes instrumentos de poder no fim da Era Clássica. Em certo sentido, o poder de regulamentação obriga à homogeneidade; mas, individualiza, permitindo medir os desvios, determinar os níveis, fixar as especialidades e tornar úteis as diferenças, ajustando-as umas às outras (FOUCAULT, 1997, p. 177)

Segundo François Delaporte (1994, p. 36), “é necessário trazer de novo estes conceitos epistemológicos ao seu contexto médico, científico e filosófico, que tornou possível, há muito tempo, seu aparecimento [...]". Por isso, é sabido que todas essas construções/definições sociais de corpo representam um arsenal histórico-cultural de neutralização das diferenças; de se criar indivíduos que carreguem o que se tem de mais homogêneo nas sociedades, de multiplicar saberes biomédicos e discursos fronteiriços com pretensão de cientificidade a qualquer custo.

A preferência ocidental dominante pela juventude e a aversão à velhice tornam-se explícitas nas preferências e padrões de consumo contemporâneos. Seu cume é atingido quando se pensa na figura política da "cultura gay" das grandes cidades e centros urbanos que valoriza, entre outras coisas, atributos corporificados de imagem e de estética, com ênfase na capacidade de gerar desejo e reificar atração pela juventude/beleza num ideal sublime de inserção social e próprio veículo à subjetivação (SIMÕES, 2004).

Uma transição bem sucedida por essa fase de crise dependeria fortemente da afeição e do apoio dos outros próximos, o que deixaria os homossexuais em séria desvantagem, porque não disporiam de filhos e de um cônjuge, enfim, dos vínculos familiares dos quais se poderia esperar apoio (SIMÕES, 2004, p. 4). 
Dessa forma, isolamento social, solidão e desdobramentos psicológicos negativos fariam parte da identidade do envelhescente que mantém relações com pessoas do mesmo sexo passando da meia-idade à velhice até sua finitude (SIMÕES, 2004). A literatura aponta que a imagem socialmente construída deste indivíduo mescla feminilidade e fragilidade como, por exemplo, a figura da "tia velha", sem grandes expectativas e com uma imagem altamente anacrônica à geração saúde (qualidade de vida) e à jovialidade psicoestética (bem-estar). Ressurge, também, a figura hipersexualizada e, por vezes, criminosa do "velho tarado" e/ou do sujeito adepto a práticas pedófilas (MOTA, 2009).

\section{As "tias velhas" patéticas, afeminadas, desprovidas de atrativos e meio gagás; as "bichas amargas" solitárias, maledicentes e deprimidas; as "mariconas" desesperadas por companhia e capazes de atacar qualquer jovem incauto: todas essas imagens compõem um elenco de assombrações que parece pesar sobre os homens homossexuais mais velhos como "virtualidades disciplinadoras" (SIMÕES, 2011, p. 17).}

Envelhecer é, portanto, estar constantemente na fronteira e marcado pelos esquadros avaliativos de qualidade de vida, fragilidade e masculinidade. Na fronteira médico-binária entre juventude (normalidade) e velhice (patologia), no culto fascista de se manter/ter um corpo perfeito milimetricamente modificado e modificável sediado cada vez mais por artefatos instrumentais modernos do que se tem de mais biomédico e normativo, em esquadros de feminilidade, onde ser velho, todavia, é relativizado a ser frágil - fragilidade -, tornando-se a masculinidade, assim, um objeto de desejo, por representar virilidade, força e inserção social (MISKOLCI, 2012).

Amartya Sen (2002) faz pensar sobre os bens materiais como agregadores de valores quando contribuem para o desenvolvimento humano. Talvez, o que se torna correlato de todo esse sistema científico-desenvolvimentista e disciplinar é, sobretudo, a fabricação social - que tende ao corpóreo - de indivíduos que envelhecem e se cristalizam nos chamados "bens materiais".

O corpo como bem material assume uma espécie de homogeneidade essencializada/nata que, em muitos momentos, faz parecer subjetividade. Essa homogeneidade como virtualidade disciplinadora, fabrica indivíduos jovens, belos, sarados, com qualidade de vida e bem-estar perfeitos. E, por isso mesmo, contribui para o que se interpela - e se entende - como "desenvolvimento humano".

Estar na fronteira e/ou nos "quadrados" classificatórios e regulamentadores é estar visível aos modelos médicos disciplinares e aos discursos especializados que apregoam juventude e vendem adequação social. E ainda que 
muitas questões historicamente apropriadas e institucionalmente definidas sejam vistas como verdadeiros modelos "científicos" de viver - envelhecer -; deve-se, no entanto, entender que o que está em jogo não se restringe a um corpo ou uma "identidade". Antes, uma alternância entre saberes e poderes que antes mesmo de serem introjetadas e se materializarem/cristalizarem, fabricam à própria noção de sujeito o que interpelar-se-á pela norma.

IDENTITIES, SPEECHES AND BORDERS: (RE) $T H I N K I N G \quad A G \mid N G$

abstract

The aging process has raised many questions about how to stay active and healthy and what is the price for that. Be by the advent of new plastic surgical techniques, be by the media or be by the social, cultural and historical consequences, the young/beautiful/muscular body has been getting more popular and relegated, conversely, the old body, the physical and social degeneration stigma. This has cost intense social adaptations to the hegemonic identity standards, to the body and health that used to be normal, reinforcing the boards of being normal and being patologic, of being young and being old, and instituting the real social esthetic "collective markers" of control and discipline/normalization.

keywords

Aging. Body. Gerontology. Speeches. Normalization.

referências

AMARTYA, Sen. Que impacto puede tener la ética. In: KLIKSBERG, Bernardo (Org.). Ética e desarrollo. Buenos Aires: El Ateneo, 2002. p. 1-10.

BRASIL. Ministério da Saúde. Atenção à Saúde da Pessoa Idosa e Envelhecimento. Brasilia: MS, 2010.

CANGUILHEM, Georges. O normal e o patológico. Rio de Janeiro: Editora Forense-Universitária, 1982.

CARVALHO, Marília G.; ADELMAN, Miriam; ROCHA, Cristina T. C. Apresentação. Revista Estudos Feministas, Florianópolis, v. 15, n. 1, p.123-130, jan./abr. 2007.

DEBERT, Guita G. A Reinvenção da Velhice. São Paulo: Editora da USP, 1999. 
DELAPORTE, Françoise. A História das Ciências segundo G. Canguilhem. In: PORTOCARRERO, Vera (Org.). Filosofia, História e Sociologia das Ciências. Rio de Janeiro: Fiocruz, 1994. p. 23-41.

FOUCAULT, Michel. Vigiar e punir. Petrópolis: Vozes, 1997.

GOFFMAN, Erving. Estigma: notas sobre a manipulação da identidade deteriorada. Rio de Janeiro: Zahar, 1978.

MANNHEIM, Karl. Sociologia. São Paulo: Ática, 1982.

MISKOLCl, Richard. Pânicos Morais e Controle Social: reflexões sobre o casamento gay. Cadernos Pagu, Campinas, v. 28, p. 101-128, jun. 2007.

Teoria Queer: um aprendizado pelas diferenças. Belo Horizonte: Autêntica Editora, 2012

A Teoria Queer e a Sociologia: o desafio de uma analítica da normalização. Sociologias, Porto Alegre, ano 11, n. 21, p. 150-182, jan./jun. 2009.

Corpos Elétricos: do assujeitamento à estética da existência. Revista Estudos Feministas, Florianópolis, v. 14, n. 3, p. 681-693, set./dez. 2006.

MOTA, Murilo P. Homossexualidade e envelhecimento: algumas reflexões no campo da experiência. SINAIS - Revista Eletrônica, Vitória, v. 1, n. 6, p. 26-51, dez. 2009. Disponível em: <http://www.adital.com.br/arquivos/artigo\%20-murilo_da_mota_artigo\%5B1\%5D. pdf>. Acesso em: 12 abr. 2014.

NERI, Anita L. Palavras-chave em gerontologia. 3. ed. Campinas: Alínea, 2008.

Qualidade de vida na velhice: enfoque multidisciplinar. Campinas: Alínea, 2007.

PRADO, Shirley D.; SAYD, Jane D. A gerontologia como campo do conhecimento científico: conceito, interesses e projeto político. Ciência \& Saúde Coletiva, Rio de Janeiro, v. 11, n. 2, p. 491-501, jun. 2006

REVEL, Judith. Michel Foucault: conceitos essenciais. São Carlos: Claraluz, 2005.

SILVA, Tomaz T. Documentos de ldentidade: uma introdução às teorias do currículo. Belo Horizonte: Autêntica, 1999.

SIMÕES, Júlio A.; FACCHINI, Regina. Nas trilhas do arco-íris: do movimento homossexual ao LGBT. São Paulo: Perseu Abramo, 2009.

SIMÕES, Júlio A. Homossexualidade masculina e curso da vida: pensando idades e identidades sexuais. In: PSICITELLI, Adriana et al. (Org.). Sexualidade e saberes: convenções e fronteiras. Rio de Janeiro: Garamond, 2004. p. 2-30.

ZAGO, Luiz F. "Armários de vidro" e "corpos-sem-cabeça" na biossociabilidade gay online. Interface, Botucatu, v. 17, n. 45, p. 419-432, abr./jun. 2013. 